\title{
Study of carbon dioxide and methane equilibrium adsorption on silicoaluminophosphate-34 zeotype and T-type zeolite as adsorbent
}

\author{
M. Salmasi • S. Fatemi • M. Doroudian Rad • \\ F. Jadidi
}

Received: 20 November 2011/Revised: 14 March 2013/Accepted: 6 May 2013/Published online: 29 May 2013

(C) Islamic Azad University (IAU) 2013

\begin{abstract}
Carbon dioxide is known as a hazardous material with acidic property that can be found as impurity in natural gas reservoirs with a broad range of 2 up to $40 \%$. Therefore, many efforts have been directed to remove and separate carbon dioxide from methane to prevent corrosion problems as well as improving the natural gas energy content. In this study, two molecular sieves, silicoaluminophosphate-34 (SAPO-34) zeotype and T-type zeolite, were synthesized by the hydrothermal method for the comparative study of adsorptive separation of carbon dioxide from methane. The synthesized adsorbents were characterized by X-ray diffraction, scanning electron microscopy, energy dispersive X-ray spectroscopy, and Brunner-Emmett-Teller techniques. These characterization tests confirmed formation of both materials with acceptable crystallinity. Both adsorbents were tested in equilibrium adsorption experiments in order to evaluate maximum capacity and adsorption affinity. Adsorption capacity of carbon dioxide and methane on SAPO-34 and zeolite $\mathrm{T}$ were measured in a pressure range of 0.1-2.0 MPa and temperature of 288, 298, and $308 \mathrm{~K}$ and fitted with the Sips and Langmuir isotherm models. The ideal selectivity of $\mathrm{CO}_{2} / \mathrm{CH}_{4}$ was determined for SAPO-34 and zeolite $\mathrm{T}$ at the studied pressures and temperatures, indicating that the molecular sieves can be properly used for $\mathrm{CO}_{2}-\mathrm{CH}_{4}$ separation or $\mathrm{CO}_{2}$ capturing from natural gas.
\end{abstract}

M. Salmasi · S. Fatemi $(\bowtie) \cdot$ M. Doroudian Rad · F. Jadidi School of Chemical Engineering, College of Engineering, University of Tehran, P.O. Box: 11365-4563, Tehran, Iran e-mail: shfatemi@ut.ac.ir

S. Fatemi

Oil and Gas Center of Excellence, College of Engineering, University of Tehran, P.O. Box: 11365-4563, Tehran, Iran
Keywords Adsorption - Carbon dioxide - Methane · Silicoaluminophosphate-34 · T-type zeolite

\section{Introduction}

Nowadays, selective removal of carbon dioxide from methane is one of the important issues of environmental engineering. Global warming is one of the most important environmental challenges, and carbon dioxide $\left(\mathrm{CO}_{2}\right)$ has classified as a hazardous gas to the environment and public health (Pires et al. 2008). In addition, $\mathrm{CO}_{2}$ is one of the important natural gas contaminants, which must be removed to increase the natural gas energy content and reduce its corrosive properties in natural gas storage and transportation (Baker 2002; Li et al. 2004; Delgado et al. 2006, 2007). The conventional method for removing $\mathrm{CO}_{2}$ from methane $\left(\mathrm{CH}_{4}\right)$ in industrial applications is amine absorption, which is a toxic and noneconomic technique (Baker 2002). Recently, adsorptive methods using nanoporous materials, which are known as efficient processes, have appealed many research groups (Cichocki and Koscielniak 1999; Poshusta et al. 2000; Harlick and Tezel 2003; Delgado et al. 2006, 2007; Belmabkhout and Sayari 2009; Himeno et al. 2007; Rivera-Ramos et al. 2008; Xu et al. 2009). Molecular sieves such as zeolites and zeotypes are nanoporous materials which are finding widespread application as a catalyst and adsorbent in industrial processes (Yan et al. 2009). The small pore size, high thermal and chemical stability of zeotype, and zeolite molecular sieves make them ideal material for use in adsorption processes (Poshusta et al. 2000). The pore diameter and surface area of the absorbents are the key parameters in its adsorption capability (RiveraRamos et al. 2008).

Separation of $\mathrm{CO}_{2}$ from $\mathrm{CH}_{4}$ has been studied using various kinds of adsorbents and membranes such as $\mathrm{X}, \mathrm{Y}$, 
MCM-41, $\beta$-zeolite, ZSM-5, silicoaluminophosphate-34 (SAPO-34), and zeolite T (Poshusta et al. 2000; RiveraRamos et al. 2008; Cichocki and Koscielniak 1999; Xu et al. 2009; Belmabkhout and Sayari 2009; Harlick and Tezel 2003; Himeno et al. 2007; Yan et al. 2009). Harlick and Tezel (2003) obtained a $\mathrm{CO}_{2} / \mathrm{CH}_{4}$ selectivity of 1.7 at $313 \mathrm{~K}$ and atmospheric pressure by using ZSM-5 with a $\mathrm{SiO}_{2} / \mathrm{Al}_{2} \mathrm{O}_{3}$ ratio of 280 . $\mathrm{Xu}$ et al. (2009) studied the adsorption of pure $\mathrm{CO}_{2}$ and $\mathrm{CH}_{4}$ on $\beta$-zeolite, and the selectivity of carbon dioxide to methane was found 4.63 at $303 \mathrm{~K}$ and 1 bar. Belmabkhout and Sayari (2009) had investigated the adsorption of carbon dioxide and methane on MCM-41 at ambient temperature and high pressures. The selectivity of $\mathrm{CO}_{2} / \mathrm{CH}_{4}$ was determined around 4.5 at atmospheric pressure.

In this research, two types of molecular sieves (SAPO-34 and T-type zeolite) were nominated due to their ability of $\mathrm{CO}_{2}$ separation from $\mathrm{CH}_{4}$. SAPO-34, as a kind of zeotype material, is a cage-type molecular sieve with framework structure similar to the naturally occurring chabazite zeolite (Lee et al. 2007). Chabazite structure has a three-dimensional pore system with ellipsoidal cages interconnected via 8 -membered ring windows with pore apertures of $0.38 \mathrm{~nm} \times 0.38 \mathrm{~nm}$ (Djieugoue et al. 2000; Denayer et al. 2008; Yan et al. 2009). This geometry allows molecules, such as $\mathrm{CO}_{2}$, with kinetic diameter of $0.33 \mathrm{~nm}$ to easily diffuse through the crystal structure (Rivera-Ramos et al. 2008). Another proposed molecular sieve for $\mathrm{CO}_{2}$ adsorption is T-type zeolite, which belongs to the offretite-erionite intergrowth family of zeolites. The frameworks of offretite and erionite are different but closely related (Yang and Evmiridis 1996). Stacking faults of these two types of zeolites not only in their synthetic samples but also in natural forms usually have been observed (Breck and Acara 1960). T-type zeolite framework often shows the same properties as erionite, especially in adsorption experiments (Mougenel and Kessler 1991). Small pores of T-type zeolite, $0.36 \mathrm{~nm} \times 0.48 \mathrm{~nm}$, allow the selective separation of different mixtures such as $\mathrm{CO}_{2}$ from $\mathrm{CH}_{4}$ (Ceckiewicz 1980; Mirfendereski et al. 2008; Cui et al. 2004a, b).

Various studies dealing with SAPO-34 zeotype and T zeolite, especially in the field of membrane applications, are reported in the literature; however, studies about their application in the adsorption process are rarely found. As mentioned in the literature, there are some reports for separation of $\mathrm{CO}_{2}$ from $\mathrm{N}_{2}$ and separation of $\mathrm{CO}_{2}$ from $\mathrm{CH}_{4}$ by $\mathrm{T}$ zeolite and SAPO-34 membrane; however, there is not found any literature about separation of $\mathrm{CO}_{2}$ from the flue gas. The ideal selectivities for $\mathrm{CO}_{2} / \mathrm{N}_{2}$ and $\mathrm{CO}_{2} / \mathrm{CH}_{4}$ have been found as 31 and 266, respectively, at $343 \mathrm{~K}$ for T zeolite membrane (Qi and Henson 1998; Poshusta et al. 2000; Cui et al. 2004a, b; Rivera-Ramos et al. 2008). Cui et al. (2004a, b) reported $\mathrm{CO}_{2} / \mathrm{CH}_{4}$ selectivity of about 3.6 on the T zeolite at $298 \mathrm{~K}$ and pressure of $0.1 \mathrm{MPa}$. Li et al. (2004) studied separation of $\mathrm{CO}_{2} / \mathrm{CH}_{4}$ by SAPO-34 membranes, and the best $\mathrm{CO}_{2} / \mathrm{CH}_{4}$ separation selectivity was found to be 67 at $297 \mathrm{~K}$. Sr ${ }^{2+}$-SAPO-34 adsorbent was the best option for $\mathrm{CO}_{2}$ removal from $\mathrm{CH}_{4}$ mixture, especially at low concentrations. This kind of adsorbent was capable of removing as much as $2.8 \mathrm{wt} \%$ at a $\mathrm{CO}_{2}$ partial pressure of 3-10 atm at room temperature (Rivera-Ramos et al. 2008). To design and produce an appropriate adsorbent for capturing $\mathrm{CO}_{2}$ and acidic gases from natural gas, a comparison between SAPO-34 and T-type zeolite is required that has not been found in the literature. In the present work, SAPO-34 zeotype and T-type zeolite are synthesized by the hydrothermal method, and their adsorptive properties are evaluated and compared in various pressures and temperatures. The evaluated properties can be used for design of the cyclic adsorption processes such as pressure swing adsorption, for selective separation of $\mathrm{CO}_{2}$ from natural gas at a wide range of pressure around normal temperatures (Li et al. 2004).

\section{Materials and methods}

\section{Adsorption apparatus}

The adsorption apparatus presented in Fig. 1 was set up to measure the equilibrium amount of adsorbed carbon dioxide and methane at three temperatures (288, 298, and $308 \mathrm{~K})$ and various operating gauge pressures $(0.1,0.3$, $0.5,0.7,1.0,1.5$, and 2.0 MPa). Helium was used as carrier gas to measure the void fractions. During each experiment, the temperature of reference and adsorption vessels was kept constant by a circulation bath. A pressure transducer was used to monitor the pressure from the beginning to the end of each experiment. Degassing of the adsorbent was performed under vacuum and high temperature (358 $\mathrm{K}$ for $3 \mathrm{~h}$ ). In order to determine the adsorption capacity, about $2.2 \mathrm{~g}$ of adsorbents was placed in the adsorption cell. After pretreatment of the adsorbent, the adsorption test started at an initial pressure and a fixed temperature, to approach to the equilibrium state. The adsorbed amount was calculated by measuring the initial pressure and pressure after equilibrium condition. The detailed illustration of the experimental setup is explained elsewhere (Rasoolzadeh et al. 2008).

Synthesis of adsorbent

Synthesis of SAPO-34 zeotype

SAPO-34 is a zeotype molecular sieve composed of $\mathrm{Al}, \mathrm{P}$, and $\mathrm{Si}$ elements. Silicoaluminophosphate gel was 
Fig. 1 Schematic of adsorption apparatus

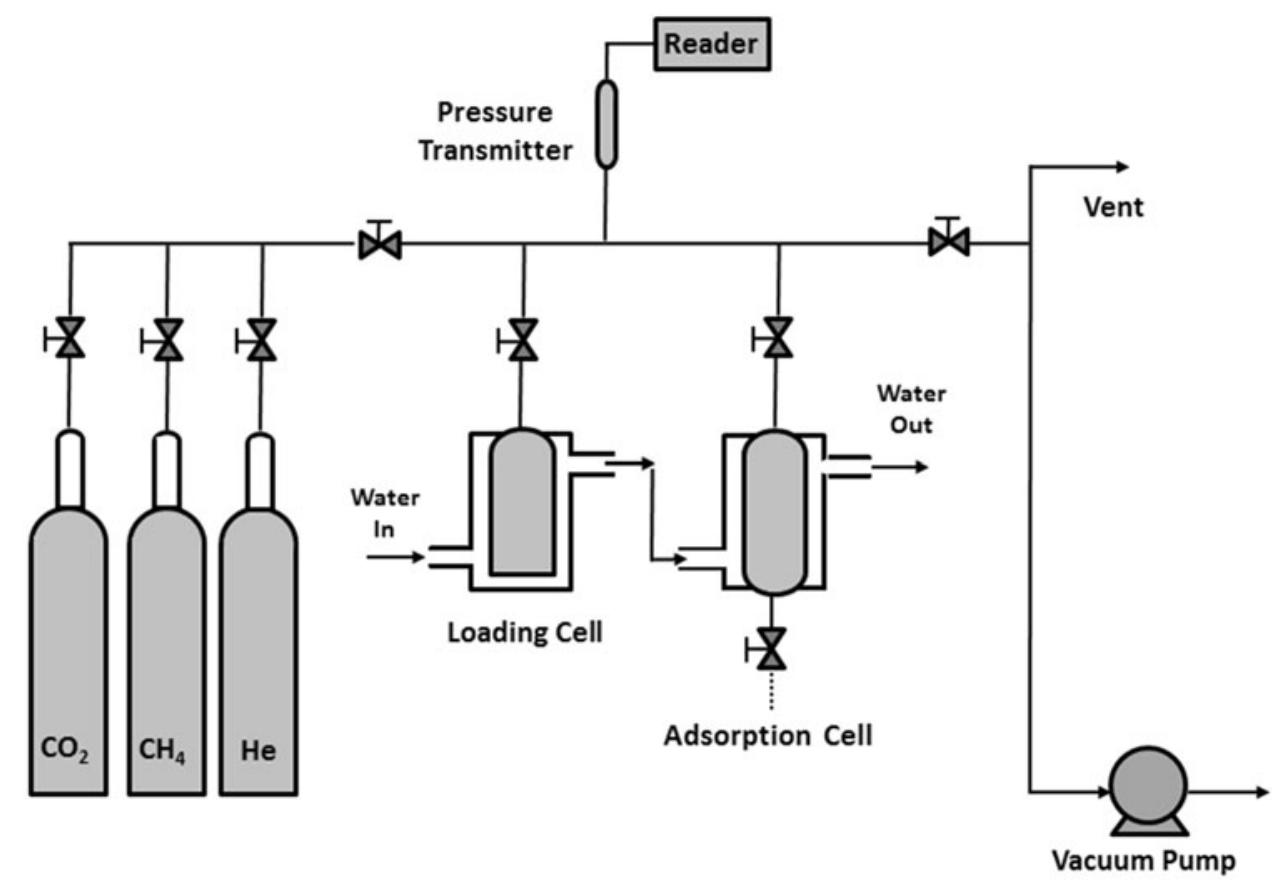

prepared from a gel composition of $\mathrm{Al}_{2} \mathrm{O}_{3}: \mathrm{P}_{2} \mathrm{O}_{5}: 0.6$ $\mathrm{SiO}_{2}$ : 1 TEAOH: 1 morpholine: $60 \mathrm{H}_{2} \mathrm{O}$. The synthesis procedure followed for gel preparation is described as following. Firstly, aluminum isopropoxide (AIP, Merck) was dissolved in a mixture of orthophosphoric acid (85 wt $\% \mathrm{H}_{3} \mathrm{PO}_{4}$, Merck) and deionized water to form aluminum sol. Mixture of colloidal silica (40 wt $\% \mathrm{SiO}_{2}$, Aldrich) and template was added to aluminum sol. In present work, tetraethylammonium hydroxide (35 wt\% aqueous solution of TEAOH, Aldrich) and morpholine (Merck) were used as the organic templates. The resulting gel was aged at room temperature for $24 \mathrm{~h}$. After the aging period, the gel was transferred into a Teflon autoclave and crystallized at $458 \mathrm{~K}$ for $48 \mathrm{~h}$. The synthesized material was recovered by centrifugation, washed several times, and then dried at $373 \mathrm{~K}$. Final product was then calcined at $873 \mathrm{~K}$ for $5 \mathrm{~h}$.

\section{Synthesis of T-type zeolite}

$\mathrm{T}$ zeolite which is composed of $\mathrm{Al}$ and $\mathrm{Si}$ elements was prepared by mixing sodium hydroxide (98 wt $\%$, Merck), potassium hydroxide ( $85 \mathrm{wt} \%$, Merck), sodium aluminate (54 wt $\% \mathrm{Al}_{2} \mathrm{O}_{3}, 41 \mathrm{wt} \% \mathrm{Na}_{2} \mathrm{O}$, Riedel-de Haen), colloidal silica (40 wt $\% \mathrm{SiO}_{2}$, Aldrich), and distilled water. The molar composition of the initial gel was $\mathrm{SiO}_{2}: 0.05$ $\mathrm{Al}_{2} \mathrm{O}_{3}: 0.26 \mathrm{Na}_{2} \mathrm{O}: 0.09 \mathrm{~K}_{2} \mathrm{O}: 14 \mathrm{H}_{2} \mathrm{O}$. T-type zeolite gel was prepared by dissolving the potassium hydroxide and sodium hydroxide in distilled water, then slowly adding sodium aluminate and colloidal silica. Then, the mixture was stirred for 1 day to ensure homogeneity. The resulting gel was placed in a Teflon lined autoclave and kept at $378 \mathrm{~K}$ in an oven for 7 days. The white solid product was washed with distilled water and then dried at $483 \mathrm{~K}$.

\section{Characterizations}

X-ray diffraction (XRD) pattern of powdered adsorbents was obtained on a powder X-ray diffractometer (Bruker D8) using $\mathrm{CuK} \alpha$ radiation $(\lambda=1.54 \AA)$. The morphology of adsorbents was confirmed using a Philips XL30 scanning electron microscope (SEM). The chemical composition of the adsorbents was determined by Oxford 2538 scanning electron microscope equipped with an energy dispersive X-ray (EDX) spectrometer. Brunner-EmmettTeller (BET) surface area was measured using nitrogen adsorption/desorption isotherms determined at $77 \mathrm{~K}$ by a Micromeritic ASAP 2010 analyzer.

\section{Results and discussion}

\section{Characterization}

XRD pattern of SAPO-34 and zeolite T is shown in Fig. 2. According to the XRD patterns, the position of peaks of both synthesized adsorbents is similar to those SAPO-34 and zeolite $\mathrm{T}$ reported in the literature (Lok and Patton 1984; Zhou et al. 2009). 


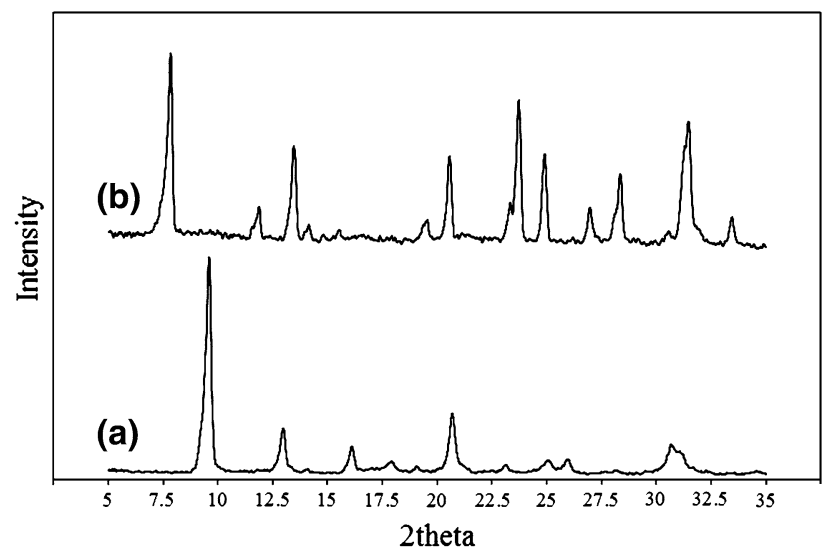

Fig. 2 XRD pattern of adsorbent: (a) SAPO-34 and (b) zeolite T

Figure 3 shows the SEM images of SAPO-34 and zeolite T. As shown, SAPO-34 and T-type zeolite have formed in cubic and rod-shaped crystals, respectively.

The composition and the BET surface area of each absorbent are given in Table 1. The BET sur'face area of synthesized SAPO-34 and zeolite T was determined 502 and $352 \mathrm{~m}^{2} / \mathrm{g}$, respectively.

\section{Adsorption process}

\section{Adsorption isotherm}

Equilibrium data of the adsorbed $\mathrm{CO}_{2}$ and $\mathrm{CH}_{4}$ were measured by the volumetric method. The equilibrium adsorption data of $\mathrm{CO}_{2}$ and $\mathrm{CH}_{4}$ were well fitted with Sips (Langmuir-Freundlich) model, which exhibited better presentation of experimental data than the other models in the studied ranges of pressure and temperature. The general form of Sips model can be observed as Eq. (1) (Do 1998).

$q=q_{\mathrm{m}} \frac{(b p)^{\frac{1}{n}}}{1+(b p)^{\frac{1}{n}}}$
Table 1 Composition of absorbents

\begin{tabular}{llllllll}
\hline Absorbent & \multicolumn{2}{c}{$\begin{array}{l}\text { BET surface area } \\
\left(\mathrm{m}^{2} / \mathrm{g}\right)\end{array}$} & \multicolumn{6}{c}{ Composition $(\mathrm{mol} \%)$} \\
\cline { 3 - 8 } & & $\mathrm{Na}$ & $\mathrm{K}$ & $\mathrm{Al}$ & $\mathrm{P}$ & $\mathrm{Si}$ \\
\hline $\begin{array}{c}\text { SAPO-34 } \\
\begin{array}{c}\text { zeotype } \\
\text { T-type zeolite }\end{array}\end{array}$ & 502 & - & - & 0.58 & 0.29 & 0.12 \\
\hline
\end{tabular}

In this equation, $p$ is the equilibrium pressure and $q_{\mathrm{m}}, b$, and $n$ are the maximum adsorption capacity, the adsorption equilibrium constant, and the parameter indicating the heterogeneity of the system, respectively. The fitting parameters $\left(q_{\mathrm{m}}, b\right.$ and $\left.n\right)$ of isotherm equations are temperature dependent and define as Eqs. (2), (3), and (4), respectively (Do 1998).

$q_{\mathrm{m}}=q_{\mathrm{m} 0} \exp \left[\chi\left(1-\frac{T_{0}}{T}\right)\right]$

$b=b_{0} \exp \left[\frac{\Delta H_{\text {ads }}}{R T_{0}}\left(\frac{T_{0}}{T}-1\right)\right]$

$\frac{1}{n}=\frac{1}{n_{0}}+\alpha\left(1-\frac{T_{0}}{T}\right)$

In above equations, $q_{\mathrm{m} 0}, b_{0}, n_{0}$, and $\chi$ are the constants of the temperature dependent equations. $T_{0}$ is the reference temperature which is equal to $288 \mathrm{~K}$ as the lowest temperature in our experiments.

The unknown parameters of Sips model were determined by the direct search method of Nelder-Mead simplex to minimize sum of squared difference of actual and model equilibrium adsorption. The correlated parameters of fitted isotherms are listed in Table 2. The heterogeneity parameter of $\mathrm{CH}_{4}$ has been obtained equal to one $(n=1)$ which present a Langmuir model behavior of $\mathrm{CH}_{4}$ isotherm. It is concluded that methane adsorption system is a homogenous energetic sites with one layer adsorption. The heterogeneity parameter of $\mathrm{CO}_{2}$ adsorption was calculated
Fig. 3 SEM photo of adsorbent: a SAPO-34 and b zeolite $\mathrm{T}$
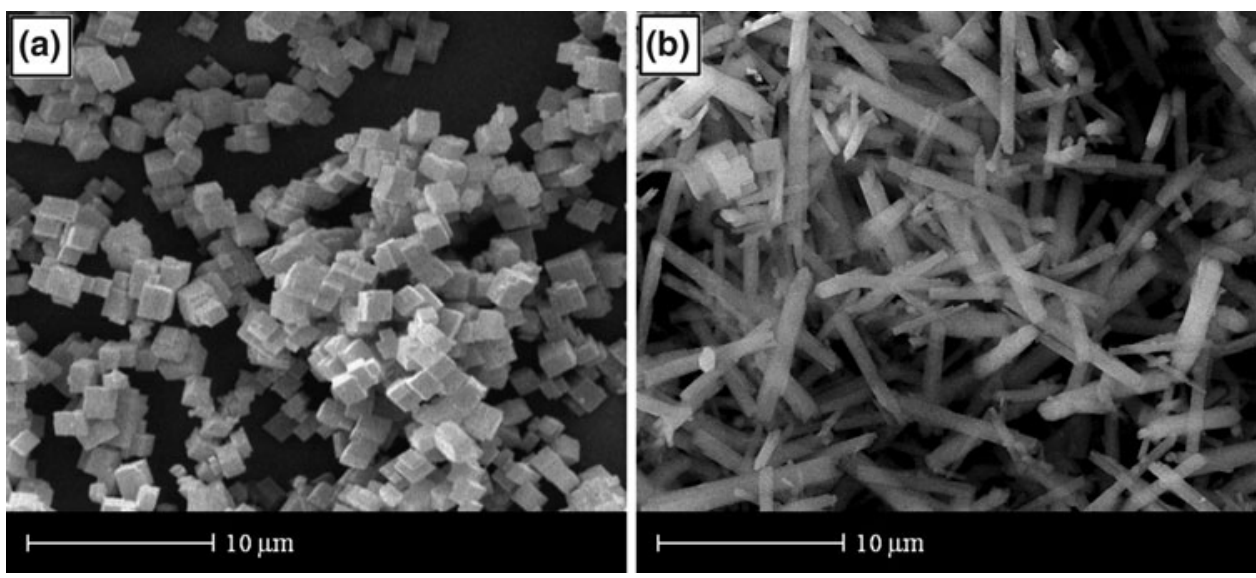
as two $(n=2)$, and this reveals a heterogeneous system for $\mathrm{CO}_{2}$ adsorption on the sites of SAPO-34 and zeolite $\mathrm{T}$ adsorbents.

The single-gas adsorption isotherms of $\mathrm{CO}_{2}$ and $\mathrm{CH}_{4}$ for SAPO-34 and zeolite T obtained at 288, 298, and $308 \mathrm{~K}$, when the gas operating gauge pressure was varied from 0.1 to $2.0 \mathrm{MPa}$, are shown in Figs. 4 and 5. Adsorption isotherms for both adsorbents show that at the same process conditions, same pressure, and temperature, $\mathrm{CO}_{2}$ adsorbed significantly more than $\mathrm{CH}_{4}$. This phenomenon can be regarded to the difference between molecular size of $\mathrm{CO}_{2}$ and $\mathrm{CH}_{4}$ as well as quadrupole property of $\mathrm{CO}_{2}$ compared to $\mathrm{CH}_{4}$. Because of the difference in kinetic diameter of $\mathrm{CO}_{2}, 0.33 \mathrm{~nm}$, and $\mathrm{CH}_{4}, 0.38 \mathrm{~nm}, \mathrm{CO}_{2}$ would pass through the molecular sieves pore mouths, whereas it might be difficult for $\mathrm{CH}_{4}$, especially at the lower pressures (Huesca et al. 1999). In addition, high quadrupole moment of $\mathrm{CO}_{2}$ against $\mathrm{CH}_{4}$ led to higher affinity of adsorbent surface for $\mathrm{CO}_{2}$. The slope of $\mathrm{CO}_{2}$ isotherm changes dramatically at low pressures, whereas at higher pressures, the adsorption capacity increases only slightly with pressure. The results in Table 2 reveal that the model parameters, $q_{\mathrm{m}}$ and $b$, increase by temperature decreasing, which is in agreement with above results. It needs to be emphasized that all calculated model parameters for $\mathrm{CO}_{2}$ are more than that of $\mathrm{CH}_{4}$.

Comparison of Figs. 4 and 5 illustrates that SAPO-34 adsorbed more amount of both components, $\mathrm{CO}_{2}$ and $\mathrm{CH}_{4}$, in contrast to zeolite $\mathrm{T}$. In the case of $\mathrm{CH}_{4}$, the higher adsorption capacity of SAPO-34 against zeolite $\mathrm{T}$ can be interpreted with respect to the kinetic diameter of $\mathrm{CH}_{4}$ and pore size of the adsorbents. The higher adsorption capacity of $\mathrm{CO}_{2}$ in SAPO-34 may arise from higher surface area of SAPO-34 in contrast to zeolite T. In addition, the more polarity of SAPO-34 in comparison with T-type zeolite, due to lower $\mathrm{Si} / \mathrm{Al}$ ratio, excels in $\mathrm{CO}_{2}$ adsorption for SAPO-34.

The heat of $\mathrm{CO}_{2}$ and $\mathrm{CH}_{4}$ adsorption, $\Delta H_{\text {ads }}$, was estimated using the Clausius-Clapeyron equation, which is expressed by Eq. (5) (Do 1998).

Table 2 The calculated isotherms parameters at each temperature

\begin{tabular}{|c|c|c|c|c|c|c|c|}
\hline Absorbent & Component & Model & Temperature (K) & $q_{\mathrm{m}}(\mathrm{mol} / \mathrm{kg})$ & $b \times 0.1\left(\mathrm{MPa}^{-1}\right)$ & $n$ & AARD \\
\hline \multirow[t]{6}{*}{ SAPO-34 } & \multirow[t]{3}{*}{$\mathrm{CO}_{2}$} & \multirow[t]{3}{*}{ Sips } & 308 & 4.92 & 0.52 & 2 & 0.048 \\
\hline & & & 298 & 5.49 & 0.54 & 2 & 0.035 \\
\hline & & & 288 & 5.99 & 0.57 & 2 & 0.028 \\
\hline & \multirow[t]{3}{*}{$\mathrm{CH}_{4}$} & \multirow[t]{3}{*}{ Langmuir } & 308 & 2.68 & 0.09 & 1 & 0.089 \\
\hline & & & 298 & 2.72 & 0.12 & 1 & 0.085 \\
\hline & & & 288 & 2.88 & 0.16 & 1 & 0.079 \\
\hline \multirow[t]{6}{*}{ Zeolite T } & \multirow[t]{3}{*}{$\mathrm{CO}_{2}$} & \multirow[t]{3}{*}{ Sips } & 308 & 3.42 & 1.01 & 2 & 0.026 \\
\hline & & & 298 & 3.56 & 1.12 & 2 & 0.027 \\
\hline & & & 288 & 3.66 & 1.31 & 2 & 0.024 \\
\hline & \multirow[t]{3}{*}{$\mathrm{CH}_{4}$} & \multirow[t]{3}{*}{ Langmuir } & 308 & 1.36 & 0.29 & 1 & 0.034 \\
\hline & & & 298 & 1.56 & 0.31 & 1 & 0.041 \\
\hline & & & 288 & 1.68 & 0.34 & 1 & 0.040 \\
\hline
\end{tabular}
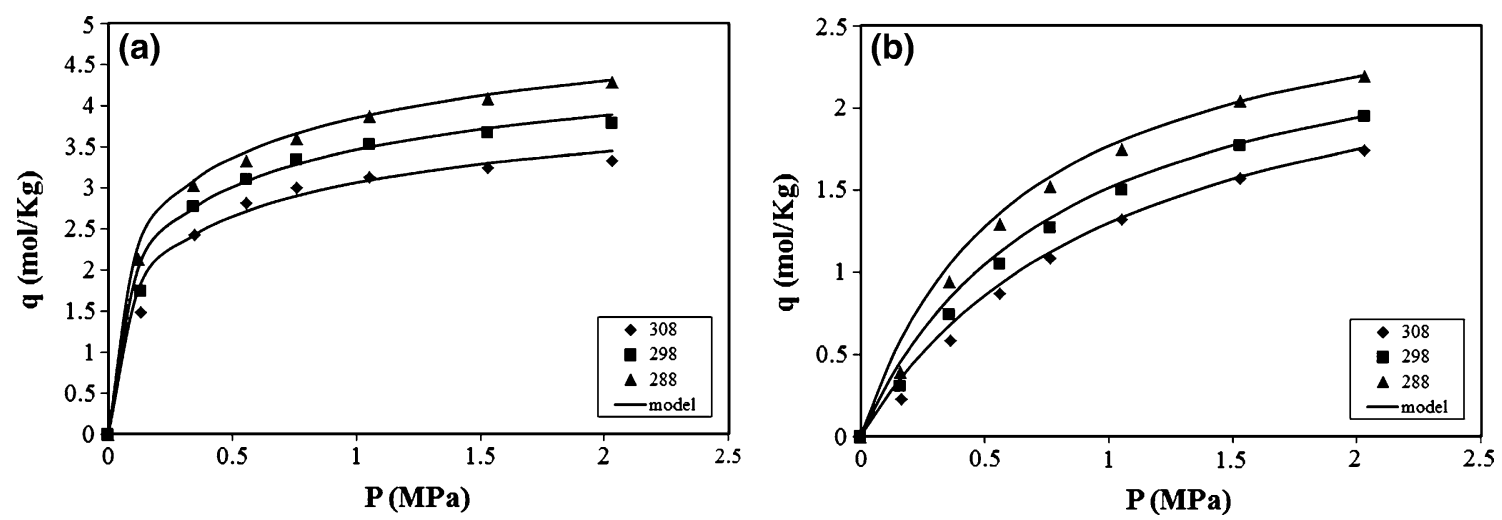

Fig. 4 Adsorption isotherm of $\mathbf{a} \mathrm{CO}_{2}$ and $\mathbf{b} \mathrm{CH}_{4}$ for SAPO-34 zeotype 

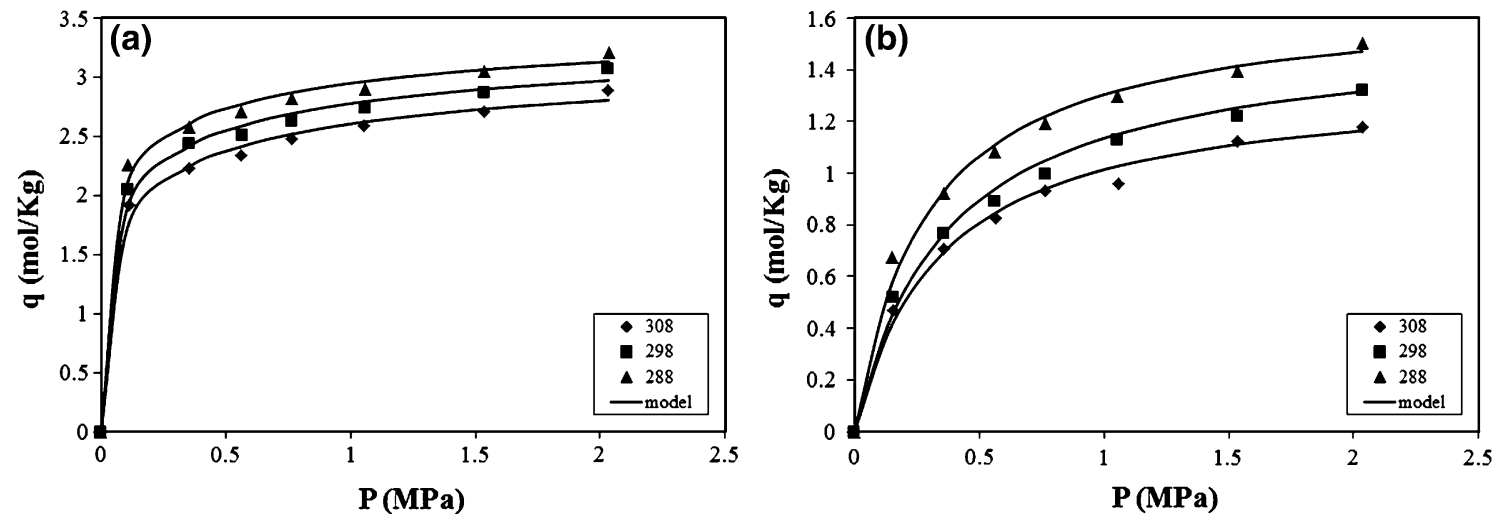

Fig. 5 Adsorption isotherm of a $\mathrm{CO}_{2}$ and $\mathbf{b} \mathrm{CH}_{4}$ for zeolite $\mathrm{T}$

Table 3 Heat of adsorption for SAPO-34 and zeolite T

\begin{tabular}{lll}
\hline Adsorbed gas & SAPO-34 & $T$ \\
\hline $\mathrm{CO}_{2}$ & 39.38 & 33.62 \\
$\mathrm{CH}_{4}$ & 24.44 & 22.30 \\
\hline
\end{tabular}

$\Delta H_{\mathrm{ads}}=\left.R \frac{\partial \ln P}{\partial(1 / T)}\right|_{q}$

It was obtained by plotting $\ln P$ versus reciprocal of temperature. The value of $\Delta H_{\text {ads }}$ is correlated with adsorption type, physical, or chemical adsorption. In addition, estimated value of $\Delta H_{\mathrm{ads}}$ is significant with respect to adsorbent regeneration. The heat of $\mathrm{CO}_{2}$ and $\mathrm{CH}_{4}$ adsorption on both adsorbents is reported in Table 3.

As shown, the resulted heats of adsorption estimated by Clausius-Clapeyron equation are in the range of physical adsorption. The values founded for $\mathrm{CO}_{2}$ are significantly higher than $\mathrm{CH}_{4}$, which can be explained in terms of smaller molecular size of $\mathrm{CO}_{2}$ against $\mathrm{CH}_{4}$ and stronger interaction of $\mathrm{CO}_{2}$ with adsorbent surface in comparison with $\mathrm{CH}_{4}$.

\section{Adsorption selectivity}

The single-component isotherm is a tool for calculating the ideal selectivity of the adsorbent for carbon dioxide against methane. Various adsorbed amounts at different pressures and temperatures are now available from the equilibrium model to find the ideal selectivity of $\mathrm{CO}_{2}$ over $\mathrm{CH}_{4}$ using the Eq. (6) (Hosseinpour et al. 2011).

Adsorption selectivity $=\frac{q_{\mathrm{eq}, \mathrm{CO}_{2}} / P_{\mathrm{eq}, \mathrm{CO}_{2}}}{q_{\mathrm{eq}, \mathrm{CH}_{4}} / P_{\mathrm{eq}, \mathrm{CH}_{4}}}$

Figures 6 and 7 exhibit the selectivity of $\mathrm{CO}_{2}$ over $\mathrm{CH}_{4}$ at three temperatures for the two adsorbents. It is evident that the selectivity of $\mathrm{CO}_{2}$ over $\mathrm{CH}_{4}$ decreases with the increase

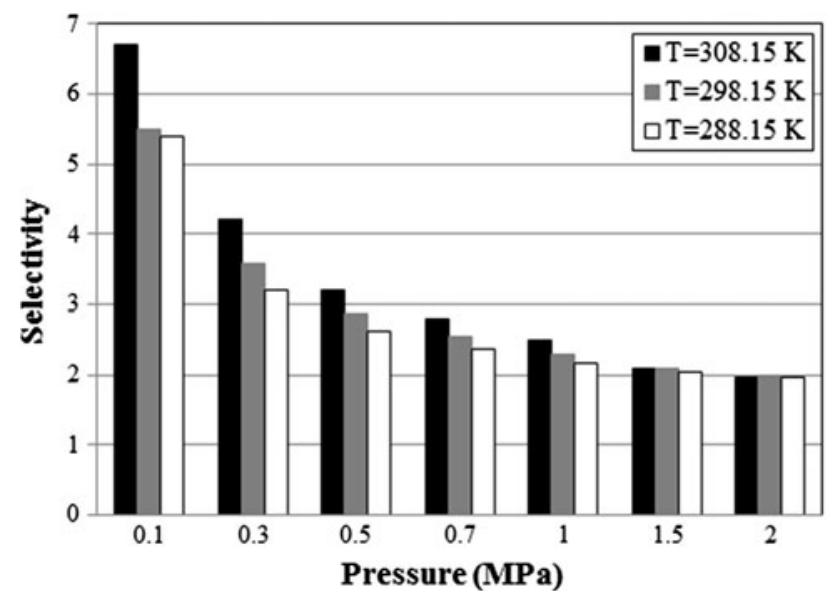

Fig. 6 Selectivity of $\mathrm{CO}_{2} / \mathrm{CH}_{4}$ for SAPO-34 zeotype

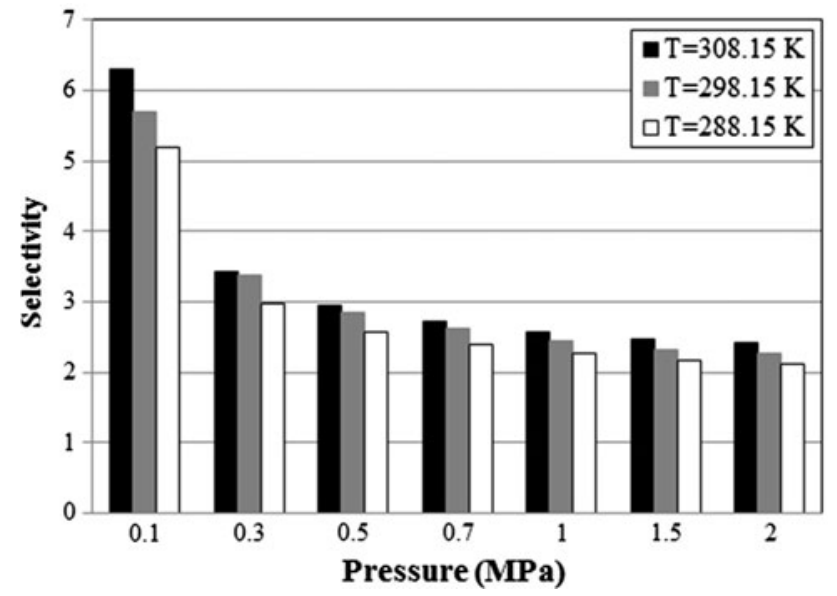

Fig. 7 Selectivity of $\mathrm{CO}_{2} / \mathrm{CH}_{4}$ for T-type zeolite

of equilibrium pressure. Significant variations in adsorption selectivity were observed in the range of pressure between 0.1 and $0.5 \mathrm{MPa}$. At the higher pressures, variation of 
selectivity was not pronounced. The highest selectivity values for both adsorbents were obtained at the atmospheric pressure. This phenomenon can be due to the higher adsorption amount of $\mathrm{CO}_{2}$ compared to $\mathrm{CH}_{4}$ at the atmospheric pressure. On the other hand, the selectivity of $\mathrm{CO}_{2}$ against $\mathrm{CH}_{4}$ rises by increasing temperature. It is according to the higher adsorbent affinity toward $\mathrm{CO}_{2}$ compared with $\mathrm{CH}_{4}$. In general, the higher adsorption capacity of $\mathrm{CO}_{2}$ can be explained by its smaller molecular size and the interaction of quadrupole moment of $\mathrm{CO}_{2}$ with the surface of adsorbents, whereas $\mathrm{CH}_{4}$ with no dipole moment and larger molecular size do not show any significant attraction to the pores and surface of the adsorbents at low pressures, and only at high pressures by creating induced polarity and London forces shows weak interaction with the adsorbents surface. Such differences between $\mathrm{CO}_{2}$ and $\mathrm{CH}_{4}$ adsorptive properties resulted to stronger effect of temperature on $\mathrm{CH}_{4}$ adsorption and desorption compared with $\mathrm{CO}_{2}$. Therefore, as it can be seen in Figs. 6 and 7, temperature increase resulted to the higher selectivities, because the adsorption amount of $\mathrm{CH}_{4}$ decreases more effectively than $\mathrm{CO}_{2}$ at higher temperatures.

\section{Conclusion}

In this research, synthesis of two nano-structured materials, SAPO-34 and zeolite $\mathrm{T}$, was conducted successfully for $\mathrm{CO}_{2}$ separation from natural gas. The performance of those materials was studied for adsorptive separation of $\mathrm{CO}_{2}$ from $\mathrm{CH}_{4}$ in a volumetric setup. The equilibrium adsorption tests were carried out and modeled at temperatures of 288, 298, and $308 \mathrm{~K}$ and pressures of $0.1,0.3,0.5,0.7,1.0$, 1.5, and 2.0 MPa. The isotherm data were fitted on Sips model for $\mathrm{CO}_{2}$ and Langmuir model for $\mathrm{CH}_{4}$ adsorption with good agreement between model and experiments. The ideal selectivity of $\mathrm{CO}_{2} / \mathrm{CH}_{4}$ was determined for both adsorbents at various pressures and temperatures. The selectivity of the adsorbents toward $\mathrm{CO}_{2}$ was more than six times higher than $\mathrm{CH}_{4}$ and this revealed the applicability of the both adsorbents for efficient separation of $\mathrm{CO}_{2}$ from $\mathrm{CH}_{4}$ at normal pressure and temperature. The produced materials with their good $\mathrm{CO}_{2}$ adsorption affinity would be appropriate candidates for dynamic adsorption processes. It should be noted that comparison between SAPO-34 and T-type zeolite has shown more ability of SAPO-34 for selective adsorption of $\mathrm{CO}_{2}$; however, there was not much significant difference between the selectivity of the studied adsorbents.

Acknowledgments This work has been carried out in Adsorption Process Lab in the School of Chemical Engineering of University of Tehran.

\section{Nomenclature}

$q \quad$ Adsorption capacity ( $\mathrm{mol} / \mathrm{kg})$

$q_{\mathrm{m}} \quad$ Maximum adsorption capacity ( $\left.\mathrm{mol} / \mathrm{kg}\right)$

$q_{\text {eq }} \quad$ Equilibrium adsorbed amount $(\mathrm{mol} / \mathrm{kg})$

$p \quad$ Pressure (MPa)

$p_{\text {eq }} \quad$ Equilibrium pressure (MPa)

$b \quad$ Adsorption equilibrium constant $\left(\mathrm{MPa}^{-1}\right)$

$T \quad$ Temperature (K)

$T_{0} \quad$ Minimum experimental temperature (K)

$n \quad$ Parameter indicating the heterogeneity of the system

$R \quad$ Gas constant $(\mathrm{kJ} / \mathrm{mol} \mathrm{K})$

$\Delta H_{\text {ads }} \quad$ Heat of adsorption $(\mathrm{kJ} / \mathrm{mol})$

\section{References}

Baker RW (2002) Future directions of membrane gas separation technology. Ind Eng Chem Res 41:1393-1411

Belmabkhout Y, Sayari A (2009) Adsorption of $\mathrm{CO}_{2}$ from dry gases on MCM-41 silica at ambient temperature and high pressure. 2: Adsorption of $\mathrm{CO}_{2} / \mathrm{N}_{2}, \mathrm{CO}_{2} / \mathrm{CH}_{4}$ and $\mathrm{CO}_{2} / \mathrm{H}_{2}$ binary mixtures. Chem Eng Sci 64:3729-3735

Breck DW, Acara NA (1960) Crystalline zeolite T. US Patent 2950952

Ceckiewicz S (1980) Effect of cation exchange in T-type zeolite on the IR spectra of sorbed methanol. React Kinet Catal Lett 13:297-304

Cichocki A, Koscielniak P (1999) Experimental designs applied to hydrothermal synthesis of zeolite ERI + OFF (T) in the $\mathrm{Na}_{2} \mathrm{O}-$ $\mathrm{K}_{2} \mathrm{O}-\mathrm{Al}_{2} \mathrm{O}_{3}-\mathrm{SiO}_{2}-\mathrm{H}_{2} \mathrm{O}$ system. Part 2. Regular study. Microporous Mesoporous Mater 29:369-382

Cui Y, Kita H, Okamoto K (2004a) Preparation and gas separation performance of zeolite T membrane. J Mater Chem 14:924-932

Cui Y, Kita H, Okamoto K (2004b) Zeolite T membrane: preparation, characterization, evaporation of water/organic liquid mixtures and acid stability. J Membr Sci 236:17-27

Delgado JA, Uguina MA, Gomez JM, Ortega L (2006) Adsorption equilibrium of carbon dioxide, methane and nitrogen onto $\mathrm{Na}$ - and H-mordenite at high pressures. Sep Purif Technol 48:223-228

Delgado JA, Uguina MA, Sotelo JL, Ruız B, Rosario M (2007) Carbon dioxide/methane separation by adsorption on sepiolite. J Nat Gas Chem 16:235-243

Denayer JM, Devriese LI, Couck S, Martens J, Singh R, Webley PA, Baron GV (2008) Cage and window effects in the adsorption of n-alkanes on chabazite and SAPO-34. J Phys Chem C 112:16593-16599

Djieugoue MA, Prakash AM, Kevan L (2000) Catalytic study of methanol to olefins conversion in four small pore silicoaluminophosphate molecular sieves: influence of the structural type, nickel incorporation, nickel location, and nickel concentration. J Phys Chem B 104:6452-6461

Do DD (1998) Adsorption analysis: equilibria and kinetics. Imperial College Press, London

Harlick PJ, Tezel FH (2003) Adsorption of carbon dioxide, methane and nitrogen: pure and binary mixture adsorption for ZSM-5 with $\mathrm{SiO}_{2} / \mathrm{Al}_{2} \mathrm{O}_{3}$ ratio of 280. Sep Purif Technol 33:199-210

Himeno Sh, Tomita T, Suzuki K, Yoshida S (2007) Characterization and selectivity for methane and carbon dioxide adsorption on the 
all-silica DD3R zeolite. Microporous Mesoporous Mater 98:62-69

Hosseinpour S, Fatemi S, Mortazavi Y, Gholamhoseini M, Takht Ravanchi M (2011) Performance of CaX zeolite for separation of $\mathrm{C}_{2} \mathrm{H}_{6}, \mathrm{C}_{2} \mathrm{H}_{4}$, and $\mathrm{CH}_{4}$ by adsorption process; capacity, selectivity, and dynamic adsorption measurements. Sep Sci Technol 46:349-355

Huesca RH, Diaz L, Armenta GA (1999) Adsorption equilibria and kinetics of $\mathrm{CO}_{2}, \mathrm{CH}_{4}$ and $\mathrm{N}_{2}$ in natural zeolites. Sep Purif Technol 15:163-173

Lee YJ, Baek SC, Jun KW (2007) Methanol conversion on SAPO-34 catalysts prepared by mixed template method. Appl Catal A 329:130-136

Li S, Falconer JL, Noble RD (2004) SAPO-34 membranes for $\mathrm{CO}_{2} /$ $\mathrm{CH}_{4}$ separation. J Membr Sci 241:121-135

Lok BM, Patton RL (1984) Crystalline silicoaluminophosphates. US Patent 4440871

Mirfendereski SM, Mazaheri T, Sadrzadeh M, Mohammadi T (2008) $\mathrm{CO}_{2}$ and $\mathrm{CH}_{4}$ permeation through T-type zeolite membranes: effect of synthesis parameters and feed pressure. Sep Purif Technol 61:317-323

Mougenel JC, Kessler H (1991) Ionic conductivity of offretite, erionite, and zeolite $\mathrm{T}$ : application to the determination of stacking faults. Zeolites 17:81-84

Pires J, Bestilleiro M, Pinto M, Gil A (2008) Selective adsorption of carbon dioxide, methane and ethane by porous clays heterostructures. Sep Purif Technol 61:161-167
Poshusta JC, Tuan VA, Pape EA, Noble RD, Falconer JL (2000) Separation of light gas mixtures using SAPO-34 membranes. AIChE J 46:779-789

Qi R, Henson MA (1998) Optimization-based design of spiral-wound membrane systems for $\mathrm{CO}_{2} / \mathrm{CH}_{4}$ separations. Sep Purif Technol 13:209-225

Rasoolzadeh M, Fatemi S, Gholambosseini M, Moosaviyan M (2008) Study of methane storage and adsorption equilibria in multiwalled carbon nanotubes. Iran J Chem Chem Eng 27:127-134

Rivera-Ramos ME, Ruiz-Mercado GJ, Hernandez-Maldonado AJ (2008) Separation of $\mathrm{CO}_{2}$ from light gas mixtures using ionexchanged silicoaluminophosphate nanoporous sorbents. Ind Eng Chem Res 47:5602-5610

Xu X, Zhao X, Sun L, Liu X (2009) Adsorption separation of carbon dioxide, methane and nitrogen on monoethanol amine modified $\beta$-zeolite. J Nat Gas Chem 18:167-172

Yan Z, Chen B, Huang Y (2009) A solid-sate NMR study of the formation of molecular sieve SAPO-34. Solid State Nucl Magn Reson 35:49-60

Yang S, Evmiridis NP (1996) Synthesis and characterization of an offretite/erionite type zeolite. Microporous Mater 6:19-26

Zhou R, Zhong S, Lin X, Xu N (2009) Synthesis of zeolite T by microwave and conventional heating. Microporous Mesoporous Mater 124:117-122 